\title{
Low-grade Endometrial Stromal Sarcoma with Unusual Metastasis to the Skull
}

\section{Sarcoma endometrial estromal de baixo grau com metástase incomum no crânio}

\author{
Antonio Santos de Araújo Júnior ${ }^{1}$ Pedro Alberto Arlant ${ }^{1} \quad$ Arnaldo Salvestrini Júnior $^{1}$ \\ Angelo Fernandez ${ }^{2}$ Marcos Fernando de Lima Docema ${ }^{3}$ Rômulo Loss Mattedi ${ }^{4}$ \\ Thales Parenti Silveira ${ }^{4}$ José Guilherme Mendes Pereira Caldas ${ }^{5}$ Mirella Martins Fazzito ${ }^{6}$ \\ ${ }^{1}$ Department of Neurosurgery, Hospital Sírio-libanês, São Paulo, SP, Brazil \\ ${ }^{2}$ Department of Thoracic Surgery, Hospital Sírio-libanês, São Paulo, \\ SP, Brazil \\ ${ }^{3}$ Department of Neuroradiology, Hospital Sírio-libanês, São Paulo, SP, Brazil \\ Address for correspondence Antônio Santos de Araújo Júnior, MD, \\ Rua Peixoto Gomide, 515, cj 96, Cerqueira César, São Paulo, \\ SP, 01409-001, Brazil (e-mail: dr.antonioaraujojr@gmail.com). \\ ${ }^{4}$ Department of Pathology, Hospital Sírio-libanês, São Paulo, SP, Brazil \\ ${ }^{5}$ Department of Interventional Neuroradiology, Hospital \\ Sírio-libanês, São Paulo, SP, Brazil \\ ${ }^{6}$ Department of Neurology, Hospital Sírio-libanês, São Paulo, SP, Brazil \\ Arq Bras Neurocir 2018;37:42-46.
}

received

July 21,2017

accepted

November 13, 2017

published online

December 15, 2017
Background Endometrial stromal sarcomas (ESSs) are the second most common uterine sarcomas. Although ESSs are often indolent, they have metastatic potential. To the best of our knowledge, there are only three reports of brain metastasis, and the present report is the first to describe a late skull metastasis of an ESS.

Case Report We describe the case of a 51-year-old woman who presented abnormal vaginal bleeding 14 years ago; she was diagnosed with an uterine mass and submitted to a hysterectomy. One year ago she presented ESS lung metastasis followed by a left parietal calvarial metastasis. The optimal treatment for metastatic ESS is controversial, but the use of progesterone and aromatase inhibitors is advisable.

Introdução Sarcoma endometrial estromal (SEE) é a segunda lesão mais frequente dentre os sarcomas uterinos. Geralmente são lesões indolentes, mas com potencial de desenvolver metástase. Até o momento há apenas três relatos de metástase cerebral, sendo este o primeiro estudo a descrever uma metástase craniana tardia dessas lesões. Relato de caso Nós descrevemos o caso de uma paciente de 51 anos de idade que apresentou há 14 anos um quadro de sangramento vaginal anormal, sendo diagnosticada uma massa uterina; a paciente foi submetida a uma histerectomia. Há um ano ela evoluiu com metástase pulmonar, seguida por metástase craniana parietal esquerda. O tratamento ideal do SEE metastático ainda é controverso, mas o uso de inibidores de aromatase é aconselhável. metástases pulmonar e craniana
DOI https://doi.org/

$10.1055 / \mathrm{s}-0037-1615257$.

ISSN 0103-5355.
Copyright (e) 2018 by Thieme Revinter

Publicações Ltda, Rio de Janeiro, Brazil
License terms

(c) $(1) \$$ 


\section{Introduction}

Endometrial stromal sarcomas (ESSs) are the second most common uterine sarcomas. ${ }^{1}$ Endometrial stromal sarcoma is a rare entity of uterine malignancy, accounting for $0.2-1 \%$ of all uterine malignancies, and for $6-20 \%$ of all uterine sarcomas. ${ }^{1}$ The annual incidence of ESS is 1-2 per 1 million women, accounting for 400-700 patients each year in Europe. ${ }^{2}$ Its clinical recognition may be difficult, and the diagnosis is often made postoperatively after a histological examination.

Endometrial stromal tumors are classified by the WHO (2003) as follows: endometrial stromal nodules (the benign lesion), ESS (previously referred to as low-grade ESS), and undifferentiated endometrial sarcoma (previously referred to as high-grade ESS). ${ }^{3}$ Although ESSs are often indolent, they have metastatic potential. ${ }^{3,4}$ The abdomen, the pelvis, the spine and the lungs are common sites of metastases; however, central nervous system metastases are very unusual. There are only three reports of brain metastasis in the literature, ${ }^{1}$ and to the best of our knowledge, the present report is the first to describe a late skull metastasis of an ESS.

Endometrial stromal sarcomas occur in women between 40 and 55 years of age. ${ }^{5,6}$ The patients commonly present with abnormal uterine bleeding, pelvic pain, and dysmenorrhea, but as many as $25 \%$ of them are asymptomatic. ${ }^{7,8}$ At presentation, extrauterine pelvic extension, most commonly involving the ovary, is found in up to $1 / 3$ of the patients. ${ }^{8}$

The pathogenesis of these lesions remains unknown, but exposure to tamoxifen and unopposed estrogens has been implicated in some cases. ${ }^{9}$ Endometrial stromal sarcomas may show a variety of morphologic appearances, including epithelial differentiation, a sex cord-like pattern, smooth muscle differentiation, and fibrous myxoid appearances. ${ }^{9}$

\section{Histopathology}

Endometrial stromal neoplasms are exclusively composed of cells resembling the endometrial stroma in its proliferative phase. Microscopic findings that unequivocally correspond to ESS include a uniform population of endometrial stromal-type cells invading the myometrium and myometrial vessels. ${ }^{10}$

High-grade tumors do not have the typical growth pattern and vascularity of low-grade tumors, and show destructive myometrial invasion rather than the lymphatic permeation of a low-grade ESS. Moreover, high-grade ESSs show marked cellular pleomorphism and brisk mitotic activity. ${ }^{11}$ Endometrial sarcomas without recognizable evidence of a definite endometrial stromal phenotype, designated as poorly-differentiated endometrial sarcomas, are almost invariably high-grade tumors. They show similarity with uterine leiomyosarcomas when the clinical presentation, imaging studies, treatment modalities, and prognosis are considered.

Immunohistochemically, the tumor cells are typically positive for CD10, vimentin, actins, WT-1, IFITM1, estrogen-receptors and progesterone-receptors. Keratin may be positive in conventional areas, but also in areas of sex cord-like and glandular differentiation. ${ }^{12}$ Areas of sex cord differentiation may also be positive for inhibin, calretinin, CD99 and Melan-A. ${ }^{13,14}$ Desmin and h-caldesmon are usually positive in areas of smooth muscle differentiation. ${ }^{15,16}$ Rarely, ESSs may contain cells with clear cytoplasm, which can be HMB45-positive. ${ }^{16}$

Cytogenetically, the most common genetic abnormality $(\sim 48 \%)$ in ESSs is $\mathrm{t}(7 ; 17)(\mathrm{p} 15 ; \mathrm{q} 21)$, resulting in the fusion of the JAZF1 and SUZ12(JJAZ1) genes at 7p15 and 17q21 respectively. ${ }^{17}$

\section{Case Presentation}

We describe the case of a 51-year-old woman who presented abnormal vaginal bleeding 14 years ago; she was diagnosed with an 11-cm uterine mass, and submitted to a hysterectomy. The surgery evolved eventless, and at that time the pathological examination revealed a typical leiomyoma.

Three-years ago, the patient observed a palpable hard nodule at her left parietal scalp, which was investigated by magnetic resonance imaging (MRI), revealing an intradiploic parietal mass suggestive of intradiploic meningioma. The patient was then followed-up annually by a neurosurgeon specialist, and submitted to MRIs without any change in the volume of the tumor up to that time.

One year ago, she complained about dyspnea with hemoptysis, and was investigated by a computed tomography (CT) scan of the chest, which revealed a justa-bronchial mass at the right upper lobe with intrabronchial extension (-Fig. 1). The patient was promptly submitted to an endobronchial biopsy followed by total gross resection of the tumor by thoracoscopic right upper lobectomy ( - Fig. 1). Histological examinations of both the resected lung and former "myoma" specimens demonstrated that the original uterine tumor was a low-grade ESS that had metastasized to the lungs.

The patient then underwent staging by whole-body CT, and brain MRI, which only confirmed the single left parietal intradiploic expansile tumor ( - Fig. 2). Since the clinical background had dramatically changed, we decided to perform a left parietal craniotomy followed by cranioplasty to obtain a further histological examination of the calvarial lesion (-Fig. 3 ).

Upon the histological examination with immunohistochemistry (IHC), the tumor showed characteristics of a low-grade ESS. The hematoxylin and eosin stain revealed a metastatic infiltration into the calvarial bone tissue, with cells resembling a "starburst" pattern (-Fig. 4). The IHC was positive for CD10, estrogen receptor, progesterone receptor and h-caldesmon, and negative for epithelial membrane antigen (EMA) ( - Fig. 4).

\section{Discussion}

Endometrial stromal sarcomas are composed of cells closely resembling normal proliferative endometrial stromal cells, and they usually have an indolent course, with an 80-100\% 5-year survival rate. ${ }^{18}$ Moreover, women with ESS are usually younger than those suffering from other types of uterine sarcomas, the most common disease to affect women between 40 and 55 years of age. Our patient was even younger, presenting the first symptoms at the age of 37 years. Some other reports confirm the occurrence of this disease in younger patients, including adolescents. ${ }^{18}$ 

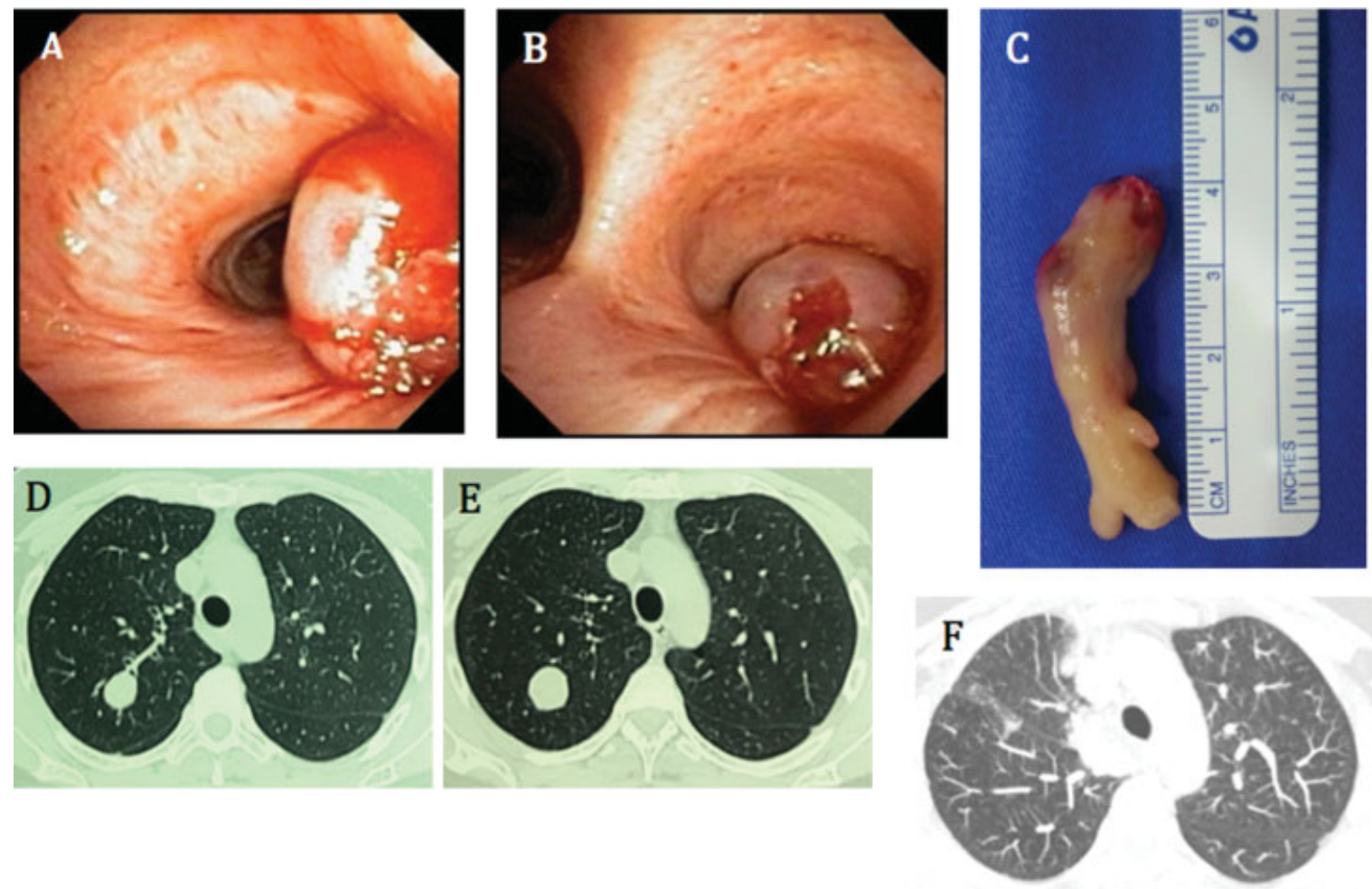

Fig. 1 (A-B) Endobronchial visualization showing a tumor obstructing the right upper airway; (C) endobronchial biopsy fragment preserving the contour of the airway; (D-E) axial chest computed tomography (CT) scan, lung view, showing a 2.2-cm nodule at the right upper lobe; (F) chest CT after right upper lobectomy.
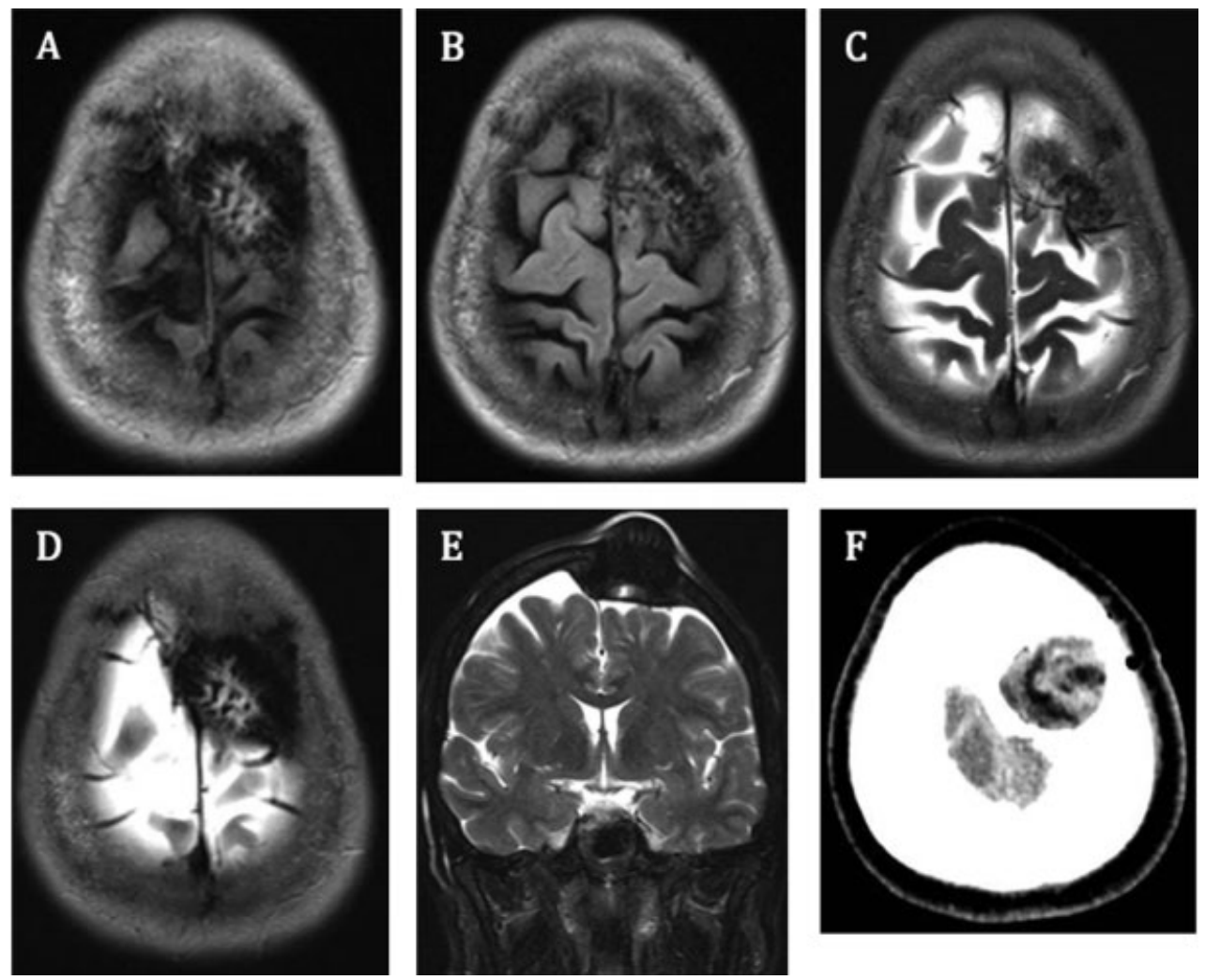

Fig. 2 (A-B) Preoperative axial fluid-attenuated inversion recovery (FLAIR) magnetic resonance imaging (MRI) scan showing a left parietal expansile bone lesion, with superficial and intracranial extension; (C-D) axial T2 MRI revealing an intradiploic trabecular lesion; (E) coronal T2 MRI; (F) brain CT showing surgical intraosseous cavity at the local of biopsy. 

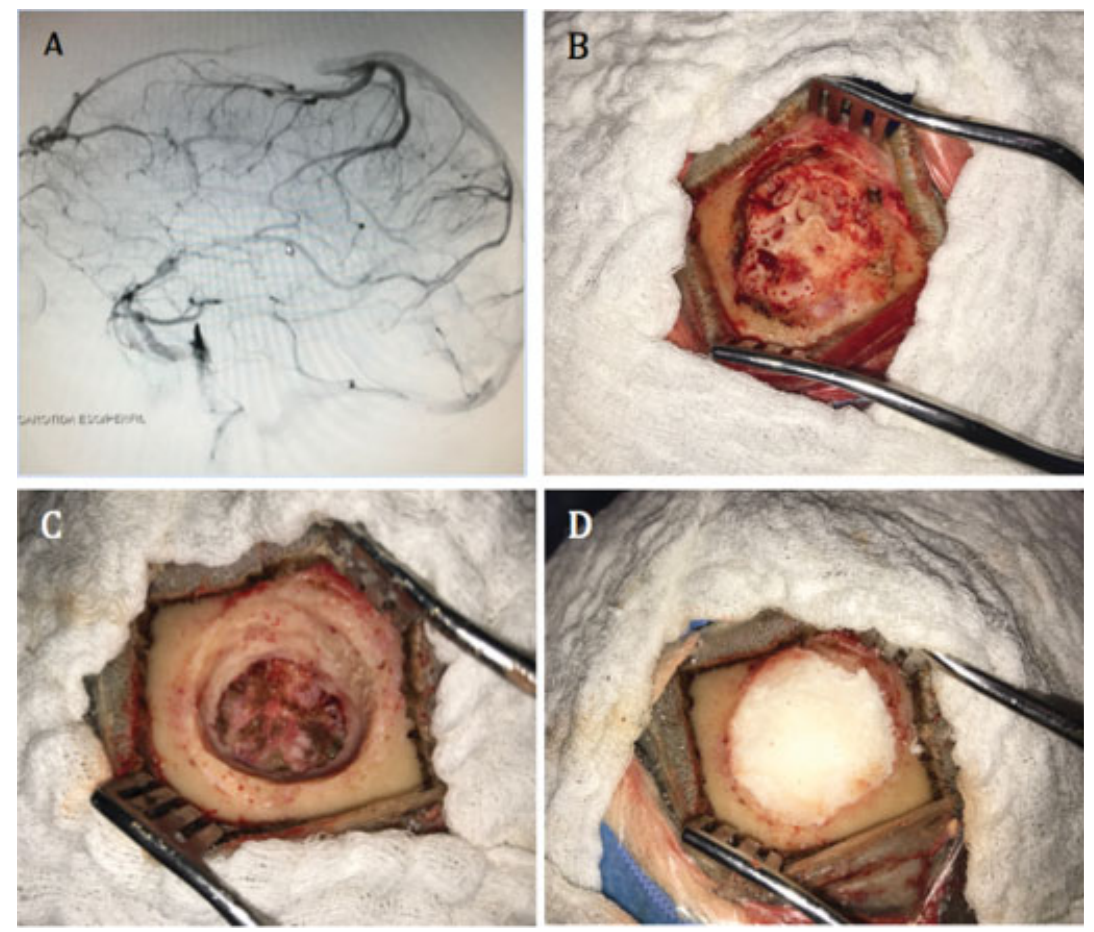

Fig. 3 (A) Preoperative left carotid artery angiogram, at side view, showing subtotal sagittal sinus occlusion, 1-cm anterior to the vein of Trolard; (B) intraoperative photo revealing a trabecular osseous lesion with minimal bleeding, with solid small fragments inside the bone tunnels; (C) intraoperative photo after drilling and biopsy of the lesion, showing meningeal thickness without invasive signs; (D) intraoperative photo after cranioplasty with methyl methacrylate.
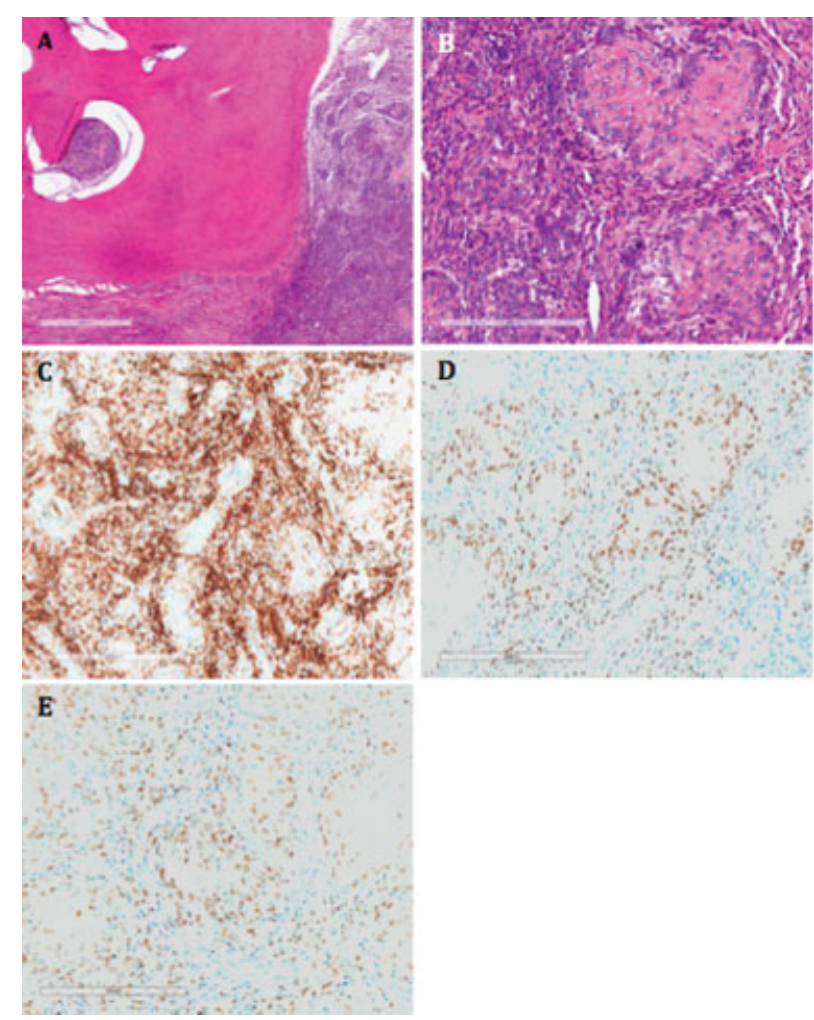

Fig. 4 (A) The neoplasm presents metastatic infiltration into the bone tissue of the skull (HE, 50X); (B) HE, 200X; (C) the immunohistochemistry (IHC) of the tumor cells are positive for CD10 (IHC 200X); (D) IHC, estrogen receptor (IHC 200X); (E) IHC, progesterone receptor (IHC 200X) and h-caldesmon.
The patients commonly present with abnormal vaginal bleeding (this was the chief complaint of our patient) and pelvic or abdominal pain; however, up to $25 \%$ of women are asymptomatic.

More than 30\% of women harboring an ESS have extrauterine disease at presentation, and the ovary is often involved in such cases. ${ }^{18}$ Regional metastases limited to the pelvis are common, including lymphatic spreading. ${ }^{18}$ Shah et al reported lymph node metastases in $7 \%$ of 384 women with ESSs, ${ }^{18}$ and up to $33 \%$ may present nodal metastases at some point in their evolution. ${ }^{19}$ Distant metastases are rare, and the organs in which they may occur include the heart, ${ }^{9}$ the lungs, ${ }^{1,2,9,12}$ the bones ${ }^{10,11}$ and the liver. ${ }^{15}$ Endometrial stromal sarcoma metastases to the brain are extremely rare, and currently there are only three cases described. ${ }^{1,16,17}$ Moreover, calvarial metastases are anecdotal. There is only one report ${ }^{10}$ of orbital ESS metastasis, with the MRI showing a $3 \times 2 \times 3$-cm lesion involving the orbital apex and the posterior cavernous sinus, infiltrating the neural foramen and extending to the sphenoid sinus and ethmoid cells.

To the best our knowledge, our report is the first to describe a delayed ESS distant metastasis to the skull. The optimal treatment for ESS with pulmonary and calvarial metastases has not yet been established. However, several case reports have been published regarding the efficacy of progesterone and aromatase inhibitors in the treatment of metastatic ESSs, ${ }^{14,19,20}$ and the guidelines for uterine neoplasms proposed by the Japan Society of Gynecologic Oncology recommend the use of hormonal therapy in cases of recurrent ESS. ${ }^{21}$ 


\section{Informed Consent}

The patient has consented to the submission of this case report to the journal.

\section{Conflicts of Interest}

The authors have no conflicts of interest to disclose.

\section{References}

1 Akhavan A, Shishebor F, Moghimi M, Binesh F. Endometrial stromal sarcoma of uterus with metastasis to the lung and brain. BMJ Case Rep 2012;2012:2012

2 Koga T, Ushijima K, Kage M, et al. Pulmonary metastasis of endometrial stromal sarcoma. Kurume Med J 2006;53(3-4):95-97

3 Behtash N, Akhavan S, Gilani MM, Mousavi A, Ghaemmaghami F, Mazhari MM. Low grade endometrial stromal sarcoma of uterine: review of 17 cases. Acta Med Iran 2011;49(09):619-624

4 Richmond AM, Rohrer AJ, Davidson SA, Post MD. Low-grade endometrial stromal sarcoma with extensive sex cord differentiation, heterologous elements, and complex atypical hyperplasia: Case report and review of literature. Gynecol Oncol Rep 2016;19:34-38

5 Nucci MR. Practical issues related to uterine pathology: endometrial stromal tumors. Mod Pathol 2016;29(Suppl 1):S92-S103

6 Amant F, Coosemans A, Debiec-Rychter M, Timmerman D, Vergote I. Clinical management of uterine sarcomas. Lancet Oncol 2009;10 (12):1188-1198

7 D’Angelo E, Prat J. Uterine sarcomas: a review. Gynecol Oncol 2010;116(01):131-139

8 Riopel J, Plante M, Renaud MC, Roy M, Têtu B. Lymph node metastases in low-grade endometrial stromal sarcoma. Gynecol Oncol 2005;96(02):402-406

9 Shakerian B, Mandegar MH, Moradi B, Roshanali F. Heart and Lung Metastases From Endometrial Stromal Sarcoma in a Forty-TwoYear-Old Woman. Res Cardiovasc Med 2015;4(03):e26066
10 Seker MM, Uslu AU, Ozer H, et al. Orbital metastasis of endocervical stromal sarcoma: a rare tumor and an uncommon metastasis. Przegl Menopauz 2014;13(06):356-358

11 Chow LT. Delayed osseous metastasis from low-grade endometrial stromal sarcoma: Uncommon occurrence deserving recognition. J Obstet Gynaecol Res 2015;41(10):1669-1675

12 Murakami A, Hayashi T, Terao Y, et al. Cystic, nodular and cavitary metastases to the lungs in a patient with endometrial stromal sarcoma of the uterus. Intern Med 2014;53(09):1001-1005

13 Xue WC, Cheung AN. Endometrial stromal sarcoma of uterus. Best Pract Res Clin Obstet Gynaecol 2011;25(06):719-732

14 Robert J. Kurman, Maria Luisa Carcangiu, C. Simon Herrington, Robert H. WHO Classification of Tumours of Female Reproductive Organs. Lyon: IARC; 2014

15 Ramia JM, De la Plaza R, Garcia I, Perna C, Veguillas P, GarcíaParreño J. Liver metastasis of endometrial stromal sarcoma. World J Hepatol 2012;4(12):415-418

16 Schick U, Bolukbasi Y, Thariat J, et al. Outcome and prognostic factors in endometrial stromal tumors: a Rare Cancer Network study. Int J Radiat Oncol Biol Phys 2012;82(05):e757-e763

17 Haberal A, Kayikçioğlu F, Boran N, Calişkan E, Ozgül N, Köse MF. Endometrial stromal sarcoma of the uterus: analysis of 25 patients. Eur J Obstet Gynecol Reprod Biol 2003;109(02):209-213

18 Shah JP, Bryant CS, Kumar S, Ali-Fehmi R, Malone JM Jr, Morris RT. Lymphadenectomy and ovarian preservation in low-grade endometrial stromal sarcoma. Obstet Gynecol 2008;112(05):1102-1108

19 Nakayama K, Ishikawa M, Nagai Y, Yaegashi N, Aoki Y, Miyazaki K. Prolonged long-term survival of low-grade endometrial stromal sarcoma patients with lung metastasis following treatment with medroxyprogesterone acetate. Int J Clin Oncol 2010;15(02):179-183

20 Pink D, Lindner T, Mrozek A, et al. Harm or benefit of hormonal treatment in metastatic low-grade endometrial stromal sarcoma: single center experience with 10 cases and review of the literature. Gynecol Oncol 2006;101(03):464-469

21 Ebina Y, Katabuchi H, Mikami M, et al. Japan Society of Gynecologic Oncology guidelines 2013 for the treatment of uterine body neoplasms. Int J Clin Oncol 2016;21(03):419-434 